\title{
Cell Proliferation after Flap Surgery, Root Conditioning and Fibronectin Application
}

\author{
R. G. Caffesse, ${ }^{\star}$ B. A. Smith, † C. E. Nasjletił and D. E. Lopatin§
}

Accepted for publication 17 October 1986

\begin{abstract}
THIS STUDY EVALUATED THE EFFECTS OF citric acid demineralization and autologous fibronectin application on cell proliferation after mucoperiosteal flap surgery. Three adult rhesus monkeys were used. After flaps were raised, the roots were surgically exposed and planed. Surfaces on the experimental sides were decalcified with citric acid, and after thorough rinsing, the inner aspect of the flaps and the roots were bathed with $1 \mathrm{ml}$ of autologous plasma fibronectin in normal saline $(400 \mu \mathrm{gm} / \mathrm{ml})$ and the flaps sutured. Contralateral teeth, acting as controls, were treated only with the surgical procedure. One hour prior to sacrifice, the animals were injected with an intravenous injection of tritiated thymidine $(1 \mu \mathrm{Ci} / \mathrm{gm}$ body weight). Surgeries were staggered to produce the following time periods: $3,7,15,21$ and 28 days. After processing, autoradiographs were obtained for evaluation, and labeled cells were counted in five compartments at $400 \times$ : (1) oral epithelium, (2) crevicular area, (3) supracrestal connective tissue, (4) coronal periodontal membrane and (5) coronal bone marrow. Forty tissue sections per procedure ( 20 slides per tooth) were counted and means obtained for the three monkeys. Differences between experimental and control values were statistically evaluated for each component, at each time interval, using pairwise $t$ tests. Fibronectin-treated areas showed significantly increased cellular proliferation $(P<0.01)$ during the first 2 weeks, affecting mainly all the supracrestal tissues. Histologically, the establishment of a well-organized fibrinous clot at 3 days was noted in these areas. Results show a faster healing after surgery with the use of citric acid and fibronectin. It was concluded that citric acid followed by fibronectin enhanced cellular proliferation.
\end{abstract}

Since Terranova and Martin ${ }^{1}$ showed increased fibroblastic attachment to scaled and acid-demineralized root surfaces in tissue culture when fibronectin was added to the medium, interest has developed relative to the effects of fibronectin during periodontal new attachment procedures.

A previous publication ${ }^{2}$ reported that dogs with natural periodontitis showed a significant increase in connective tissue attachment when modified Widman flap surgery was performed after the roots were decalcified with citric acid and the area bathed with commercially available human fibronectin. It has also been reported, ${ }^{3}$ in the same model, significant improvement was shown in the closure of furcations under similar circumstances. It is postulated that the addition of fibronectin may promote the splicing of connective tissue fibers from

\footnotetext{
* Professor and Chairman, Department of Periodontics, The University of Michigan School of Dentistry, Ann Arbor, MI 48109.

$\dagger$ Associate Professor, Department of Periodontics, The University of Michigan School of Dentistry.

$\ddagger$ Dental Research Program, V.A. Medical Center, Ann Arbor, MI.

$\S$ Dental Research Institute, The University of Michigan School of Dentistry.
}

the flap with those exposed on the root surface by acid demineralization. Furthermore, fibronectin may also promote an early "fibrin linkage" that, as suggested by Polson and Proye, ${ }^{4}$ could be the first step in promoting attachment of the tissues to the teeth. This mechanism of attachment may be definitive or it may be effective initially in holding the epithelial migration along the root surface. If the latter is the case, it may later be replaced by new attachment originating from the coronal proliferation of the periodontal membrane. ${ }^{5}$

In recent and current studies involving fibronectin, we have isolated the glycoprotein from the plasma of the same subject, following the technique proposed by Mosesson and Umfleet. ${ }^{6}$ This is the first report using autologous fibronectin.

The purpose of the present study was to evaluate the effects of citric acid demineralization and autologous fibronectin application on cell proliferation after mucoperiosteal flap surgery.

\section{MATERIALS AND METHODS}

Three adult male rhesus monkeys were used in the study. One week prior to the surgery, all teeth were thoroughly scaled and polished. A total of 30 experi- 
mental segments was treated with mucoperiosteal flap procedures aiming at new attachment or readaptation using modified Widman flap. ${ }^{7}$

Each segment consisted of two teeth, first and second premolars, first and second molars and maxillary central and lateral incisors. The experimental quadrants received surgery plus citric acid followed by fibronectin application while the contralateral segments acting as controls received only surgery.

After the mucoperiosteal flaps were raised, the roots were surgically exposed and planed, the root surfaces on the experimental sides were decalcified. For this, a

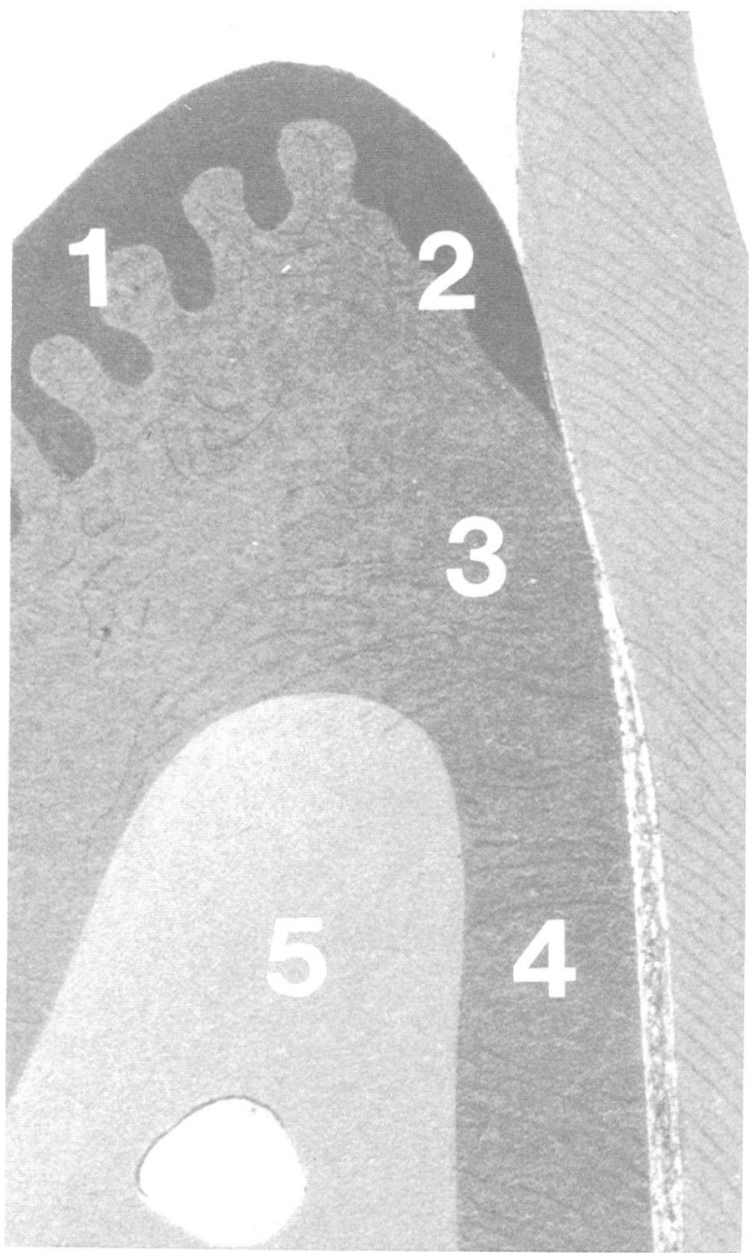

Figure 1. Schematic diagram indicating the five areas where counting was performed. saturated citric acid solution ( $\mathrm{pH} 1.0)$ was applied with cotton pledgets for 3 minutes. After thorough rinsing with saline, the inner aspect of the flaps and the root surfaces was bathed with $1 \mathrm{ml}$ of the fibronectin solution. Fibronectin application was accomplished using a $1-\mathrm{ml}$ tuberculin syringe.

Suturing was accomplished. Three minutes of moderate pressure with a moist sterile gauze was then applied to ensure good flap adaptation and also to promote a thin fibrin clot.

The fibronectin used was isolated and purified from autologous blood plasma employing the method of Mosesson and Umfleet. ${ }^{6}$ The fibronectin was $>95 \%$

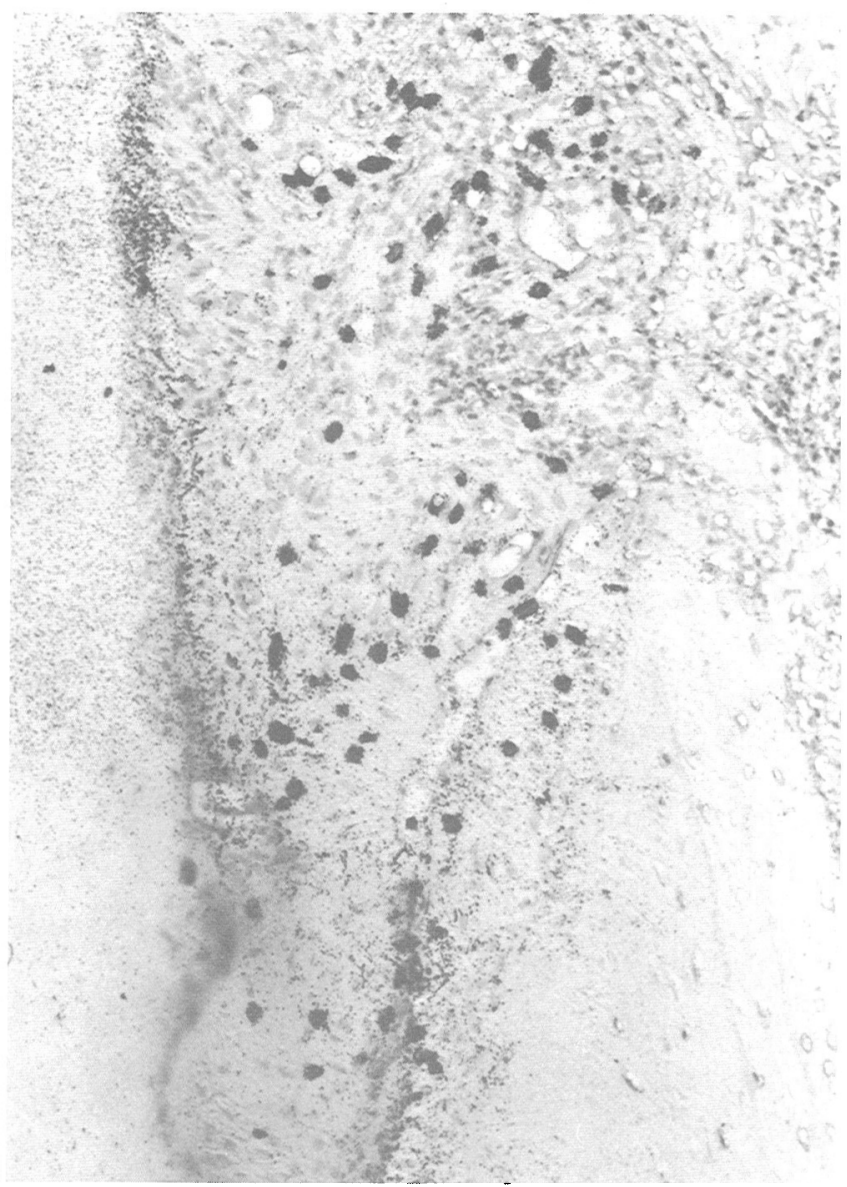

Figure 2. Three days' fibronectin specimen. Observe labeling in Areas 3 and 4 (hematoxylin $\times 100$ ).

Table 1

Thymidine-Labeled Cells at Different Observation Times $(N=3)$

\begin{tabular}{|c|c|c|c|c|c|c|c|c|c|c|}
\hline \multirow{2}{*}{ Area } & \multicolumn{2}{|c|}{3 Days } & \multicolumn{2}{|c|}{7 Days } & \multicolumn{2}{|c|}{15 Days } & \multicolumn{2}{|c|}{21 Days } & \multicolumn{2}{|c|}{28 Days } \\
\hline & $\mathrm{FN}$ & C & FN & $\mathrm{C}$ & $\mathrm{FN}$ & $\mathrm{C}$ & FN & C & $\mathrm{FN}$ & $\mathrm{C}$ \\
\hline 1 & 94.1 & $56.1^{*}$ & 102.8 & $81.0^{*}$ & 56.8 & $46.8^{*}$ & 35.2 & $43.8^{*}$ & 57.2 & 57.3 \\
\hline 2 & 38.9 & $6.7^{*}$ & 30.3 & 30.9 & 64.3 & $42.9^{*}$ & 23.6 & 25.0 & 37.5 & 39.3 \\
\hline 3 & 57.4 & $24.4^{*}$ & 68.0 & $47.8^{*}$ & 39.3 & $23.4^{*}$ & 6.8 & 7.5 & 25.0 & $21.8^{*}$ \\
\hline 4 & 16.4 & 12.4 & 78.0 & $21.6^{*}$ & 6.4 & $1.4^{*}$ & 1.0 & $1.7^{*}$ & 1.7 & 1.7 \\
\hline 5 & 6.3 & 6.0 & 43.3 & $13.8^{*}$ & 3.8 & 2.2 & .9 & .5 & 1.1 & 1.8 \\
\hline
\end{tabular}

* Pairwise $t$ test $<0.01$. 
pure as assayed by sodium dodecyl sulfate (SDS) polyacrylamide gel electrophoresis. The freeze-dried fibronectin was stored at $-20^{\circ} \mathrm{C}$ until used. On the day of surgery, bottles containing fibronectin were allowed to come to room temperature, after which fibronectin was mixed with continuous stirring into sterile saline. The final concentration of the fibronectin solution used was $400 \mu \mathrm{gm} / \mathrm{ml}$.

Surgeries were staggered to provide observation times at 3, 7, 15,21 and 28 days following surgery. One hour prior to sacrifice, each monkey received an intravenous injection of tritiated thymidine, $1 \mu \mathrm{Ci} / \mathrm{gm}$ of body weight (specific activity $6.7 \mathrm{Ci} / \mathrm{mmol}$ ).

After the monkeys were sacrificed by exsanguination, tissue blocks were removed, sectioned, fixed and decalcified. Paraffin-embedded tissue blocks were serially sectioned buccolingually at $6 \mu \mathrm{m}$. Every third tissue section was placed on a glass slide and processed for autoradiographic study. Tissue sections were stained with either hematoxylin and eosin or Mallory's connective tissue stain.

Autoradiographic Evaluation. After processing, epithelial-, connective tissue- and bone marrow-labeled cells were counted under the microscope at $400 \times$ magnification, both in experimental and control teeth. For this, the periodontium was divided into five different spatial compartments (Fig. 1): Area 1 encompassed the basal cell layer of the oral gingival epithelium. Area 2 comprised the crevicular area. Area 3 included the connective tissue cells of the supracrestal area. Area 4 comprised the connective tissue cells located in the coronal one-third of the periodontal membrane. Area 5 included bone marrow cells located in the coronal one-third of the alveolar bone.

At each time point, 40 slides/procedure (20 slides/ tooth) were counted. Means were subsequently obtained for the three monkeys. Differences between experimental and control values were statistically evaluated for each component, at each time point, using pairwise $t$ tests.

\section{RESULTS}

In the autoradiographic evaluation the fibronectintreated areas demonstrated significantly increased cellular proliferation during the first 2 weeks, affecting mainly all the supracrestal tissues (Table 1). Of special interest was the response to therapy found in Area 3,

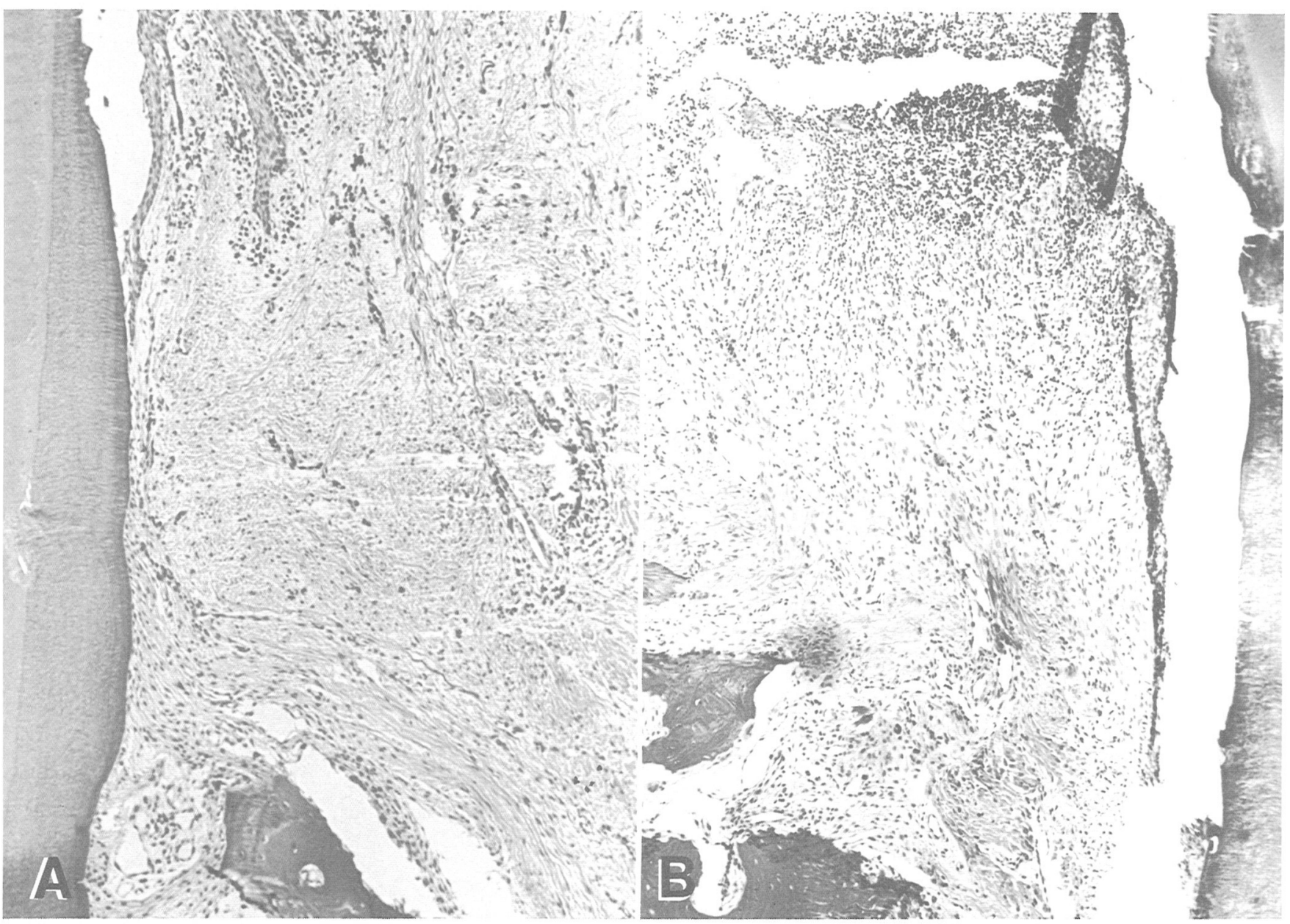

Figure 6. Seven-day specimens. A. Fibronectin-treated, showing good adaptation. B. Control, depicting lack of adaptation of the tissues to the tooth surface $(H \& E \times 50)$. 
i.e., the connective tissue cells of the supracrestal area. Significant increased labeling was found when fibronectin was applied. Similarly, an increased response was found in Area 4, connective tissue cells located in the coronal one-third of the periodontal membrane, at 7 and 15 days. However, Area 5, coronal bone marrow cells, showed increased activity only at 7 days (Figs. 2 and 3).

Control areas showed significant increases in labeling at 21 days only for Areas 1 and 4, and the highest values achieved for control areas never reached the peak values scored for experimental zones.

Histologically, a clear difference was seen at 3 days in the degree of tissue adaptation achieved when fibronectin was used (Figs. 4A and 4B). A fibrinous mesh developed holding the tissues to the roots and the bone (Fig. 5). Increased radioactivity was evident in the supracrestal connective tissues and also in the periodontal membrane (Fig. 2). Conversely, in controls the activity was less, and the tissues did not show such a degree of adaptation nor the fibrin linkage (Figs. 6A and $6 \mathrm{~B})$.

At 7 days, healing continued to be advanced in the

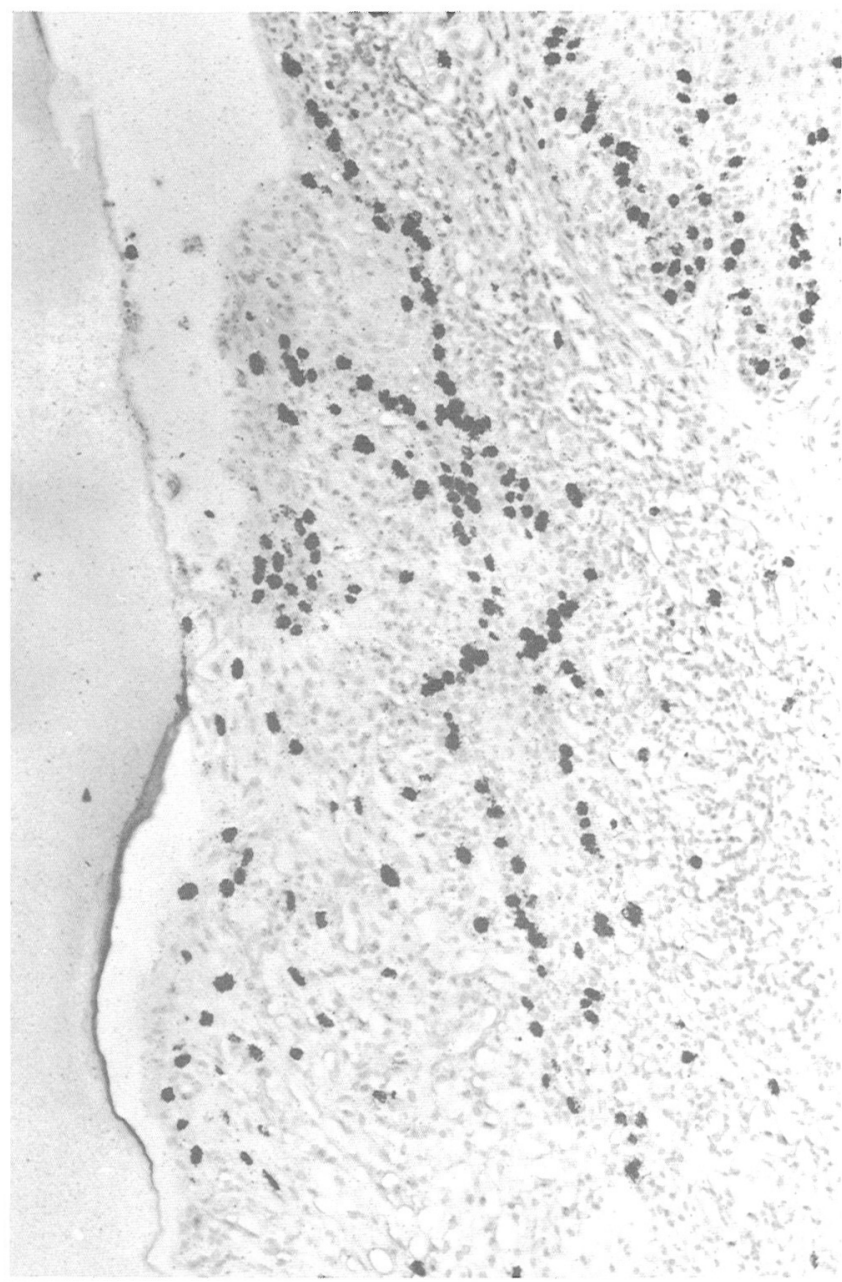

Figure 7. Seven days' fibronectin specimen. Labeling in Areas 2 and 3 (hematoxylin $\times 100$ ). experimental group, and labeling was significantly increased in Area 3 (Figs. 7 and 9). Control areas depicted reduced healing labeling compared with the fibronectintreated areas (Fig. 8).

A similar pattern continued at 15 and 21 days in the
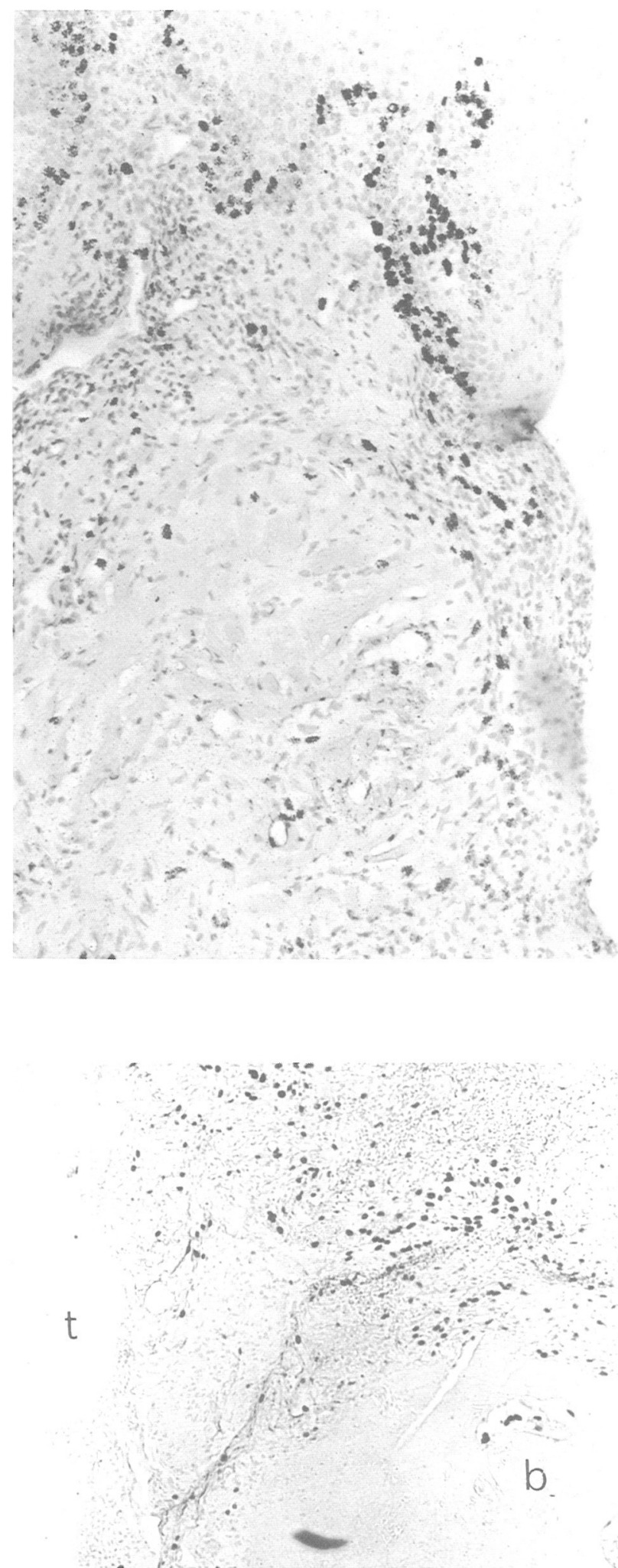

Figure 9. Seven-day fibronectin specimen. Observe tissue adaptation and labeling in Area 4. b, alveolar crest; $\mathrm{t}$, tooth (hematoxylin $\times 50$ ). 
experimental areas. Epithelium had covered the crevicular area and the supracrestal connective tissue depicted good adaptation to the roots. Improved organization of this connective tissue was found at 21 days, with fibers arranged perpendicular to the root surfaces. Labeling was reduced throughout.

Controls at 21 days showed incomplete epithelial coverage, poor adaptation of the connective tissues to the roots and delayed organization and maturation of the supracrestal tissues. Histologic findings at 28 days showed a pattern similar to the one just described.

\section{DISCUSSION}

Although the main function of fibronectin seems to be the promotion of cell adhesion, ${ }^{7,8}$ other studies have also shown that fibronectin causes a chemoattracting effect on fibroblasts and mesenchymal cells that may play an important role in wound repair. ${ }^{9,10}$ The results of the present study clearly indicate, also, an increase in cell proliferation after mucoperiosteal flap surgery when the surgical technique was supplemented by root demineralization and fibronectin application. This, in turn, produced faster healing as depicted by the development of an early fibrin mesh establishing the linkage of the tissues to the teeth and bone and by the faster organization of the connective tissues.

The use of the glycoprotein increased significantly the proliferation of the connective tissue cells from the supracrestal area and from the coronal periodontal membrane. It is impossible to differentiate in this study which one of these two areas was responsible for the repopulation of the root surface. What could be established was the fact that both sources are active in the process of repopulation. Minimal activity was noticed within the bone marrow spaces except at 7 days. It may be that the bone marrow is not a significant source for cell repopulation.

Within the limited time of this project, no root resorption was observed. It might have developed later; however, using the same animal model to study tooth replantation, we have reported initial root resorption as early as 15 days after the procedure. ${ }^{11}$
In essence, the results show a faster healing after surgery when autologous fibronectin, together with citric acid, is used.

\section{CONCLUSION}

Within the limits of this study, it can be concluded that the use of citric acid and autologous fibronectin enhances cellular proliferation and promotes faster healing after flap surgery.

\section{REFERENCES}

1. Terranova, V. P., and Martin, G. R.: Molecular factors determining gingival tissue interaction with tooth structure. $J$ Periodont Res 17: 530, 1982.

2. Caffesse, R. G., Holden, M. J., Kon, S., and Nasjleti, C. E.: The effect of citric acid and fibronectin application of healing following surgical treatment of naturally occurring periodontal disease in Beagle dogs. J Clin Periodontol 12: 578, 1985.

3. Smith, B., Caffesse, R., Nasjleti, C., et al.: Effects of citric acid and fibronectin and laminin application in treating periodontitis. $J$ Clin Periodontol, in press.

4. Polson, A. M., and Proye, M. P.: Fibrin linkage: a precursor for new attachment. J Periodontol 54: 141, 1983.

5. Nyman, S., Gottlow, J., Karring, T., and Lindhe, J.: The regenerative potential of the periodontal ligament. An experimental study in the monkey. J Clin Periodontol 9: 157, 1982.

6. Mosesson, M. W., and Umfleet, R. A.: The cold-insoluble globulin of human plasma. I. Purification primary characterization, and relationship to fibrinogen and other cold-insoluble fraction components. J Biol Chem 245: 5728, 1970.

7. Boyko, G. A., Brunette, D. M., and Melcher, A. H.: Cell attachment to demineralized root surfaces in vitro. $J$ Periodont Res 15: 297, 1980.

8. Fernyhough, W., and Page, R. C.: Attachment, growth and synthesis by human fibroblasts on demineralized or fibronectintreated normal and diseased tooth roots. J Periodontol 54: 133, 1983.

9. Kleinman, H.: Interactions between connective tissue matrix macromolecules. Connect Tissue Res 10: 61, 1982.

10. Mensing, H., Pontz, B. F., Muller, P. K., and Gauss-Muller, V.: A study on fibroblast chemotaxis using fibronectin and conditioned medium as chemoattractants. Eur J Cell Biol 29: 268, 1983.

11. Nasjleti, C. E., Caffesse, R. G., Castelli, W. A., and Hoke, J. A.: Healing after tooth reimplantation in monkeys. A radioautographic study. Oral Surg 39: 361, 1975.

Send reprint requests to: Dr. R. G. Caffesse, Department of Periodontics, The University of Michigan School of Dentistry, Ann Arbor, MI 48109. 